\title{
ARTICLE
}

\section{Histomorphological perspectives of preputial and clitoral glands of soft-furred field rat Millardia meltada}

\author{
Thangavel Rajagopal1,2*, Ganesan Ramya Vaideki ${ }^{1}$, Ganesan Saibaba ${ }^{2}$, Ponnirul \\ Ponmanickam ${ }^{2,3}$, Shanmugam Achiraman 2,4 , Swaminathan Rajanarayanan ${ }^{2,5}$ Mohammad \\ Abdulkader Akbarsha6, Govindaraju Archunan²*
}

\author{
1Department of Zoology, Thiagarajar College (Autonomous), Madurai-625 009, Tamil Nadu, India. \\ 2Pheromone Technology Lab, Department of Animal Science, School of Life Sciences, Bharathidasan University, \\ Tiruchirappalli - 620 024, Tamil Nadu, India. \\ ${ }^{3}$ Department of Zoology, Ayya Nadar Janaki Ammal College (Autonomous), Sivakasi-626 124, Tamil Nadu, India. \\ ${ }^{4}$ Department of Environmental Biotechnology, School of Environmental Science, Bharathidasan University, \\ Tiruchirappalli - 620 024, Tamil Nadu, India. \\ ${ }^{5}$ Department of Biotechnology, St. Michael College of Engineering and Technology, Kalayarkoil-630 551, Tamil \\ Nadu, India. \\ ${ }^{6}$ Research Co-ordinator, National College (Autonomous), Tiruchirappalli, 620001, Tamil Nadu, India.
}

\begin{abstract}
The present study was an attempt to understand the sexual dimorphism of the integumentary scent glands of soft-furred field rat Millardia meltada from the perspectives of anatomy, morphology and histology with view to correlate with the sex-specific pheromones they produce. The scent gland of male is known as preputial gland, and female, the clitoral gland. The rats, that are agricultural pests were field caught, the glands of males and females of almost identical size were dissected out, and subjected to gravimetric, morphometric and histological analyses. Both glands are yellowish-brown, pear-shaped, and dorsoventrally compressed. The mean weight, length and width of preputial glands are significantly $(p<0.05)$ larger than that of the clitoral glands. The preputial gland is composed of sebaceous glandular lobules and apocrine glandular lobules whereas the clitoral gland is formed only of sebaceous glandular lobules. The sebaceous glandular lobules of both preputial and clitoral glands are filled with a wax-like material. Thus, the scent glands of the soft-furred male field rats exhibit sexual dimorphism in respect histoarchitecture of the glands and the nature of the secretory material. This sexual dimorphism of the scent glands may reflect control by male and female sex hormones impinging on specific roles as sex attractant pheromones.
\end{abstract}

Acta Biol Szeged 64(2):181-189 (2020)

\section{KEY WORDS}

apocrine glandular lobes clitoral gland myoepithelial cells preputial gland sebaceous glandular lobes soft-furred field rat

\section{ARTICLE INFORMATION}

Submitted

11 January 2021

Accepted

14 January 2021

*Corresponding author

E-mail: deer_raj@yahoo.co.in (T. Rajagopal); garchu56@yahoo.co.in (G. Archunan)

\section{Introduction}

Rodent pests, distributed worldwide, are a huge menace in that they affect human health by spreading diseases and human welfare by damaging food crops and stored food grains. Soft-furred field rat, Millardia meltada, is one such rodent pest widely distributed in India, Pakistan, Nepal, Bangladesh and Sri Lanka, mostly found in gravelly areas, bunds of fields, largely cultivated areas of tropical and sub-tropical dry deciduous forests, tropical grasslands, irrigated croplands and grasslands with gravel, wherein the preferred habitats are agriculture lands, water courses, embankments, and dry rocky hills. This rat's infestation causes pre-harvest losses of up to $1-10 \%$ in rice and wheat crops (Greaves 1989). The very high reproductive fitness of rats in general and field rat in particular overrides the conventional pest control strategies whereupon control of this pest has been gruesome. Effective olfactory (chemical) communication between male and female rats plays a vital role in this high reproductive fitness (Archunan 2009). In most mammals, the olfactory communication is mediated by pheromones which are emitted into the environment via urine, feces, saliva, and the secreted fluids of diverse integumentary scent glands. Laterocaudal, supraorbital, orbital, circumcaudal, infracaudal, preputial, clitoral, armpit, metatarsal, tarsal, preorbital, interdigital, flank, cheek, chin, anal, perineal, ventral, midventral, supracaudal, etc. are some such integumentary scent glands. They are located under the dermal layer of the skin (Balakrishnan and Alexander 1985; Archunan and Ponmanickam 2010; Rajagopal and Archunan 2011; Alexandre-Pires et al. 2014; Yilmaz et al. 2017).

Among the integumentary scent glands of rats prepu- 
tial glands in the male and clitoral glands in the female are very prominent (Kannan et al. 1998; Kannan and Archunan 2001; Archunan and Ponmanickam 2010). These two glands are the prime sources of pheromones in rats and have several critical functions including conspecific attraction through releasing specific volatiles as well as non-volatile substances, mother-young bondage, etc. (Archunan 2009; Archunan and Ponmanickam 2010). According to Zhang et al. (2008) the male rats are attracted towards the females by odors emanating from the clitoral gland and this attraction is more at the time of estrus than the other phases of the reproductive cycle. Achiraman et al. (2011) found the concentration of squalene to be significantly higher in clitoral gland secretion at the time of estrus which, therefore, could be an ovulation-indicating chemosignal in female rat. Zhang et al. (2008) identified farnesol in female rats and squalene in male rats as the major chemosignals. The predominant pheromone compound farnesol and its carrier protein $\alpha_{2 \mathrm{u}}$-globulin have been reported in preputial gland secretion of the laboratory rat (Ponmanickam and Archunan 2006; Ponmanickam et al. 2009; Ponmanickam et al. 2010) and house rat (Kamalakkannan et al. 2006; Rajkumar et al. 2010). The preputial gland becomes atrophied after castration, and testosterone replacement restores it to its the original size, which suggest that the preputial gland and the glandular proteins, visa vi pheromone carrier protein, are testosterone dependent (Kamalakkannan et al. 2006; Ponmanickam et al. 2010). It is interesting to note that rat pub preputial gland releases a pheromone, dodecyl propionate, which regulates the maternal anogenital licking behavior that forms an aspect of the mother-young bond (Brouette-Lahlou et al. 1999; Ponmanickam et al. 2009). The preputial gland also enhances the poison bait efficiency by inhibiting the bait shyness when tested in house rat (Selvaraj and Archunan 2006).

The histomorphology of male preputial and female clitoral glands has been studied in a very few rat and mouse species. For instance, Knoblaugh et al. (2018) found that the preputial glands of rats and mice are lobulated and consist of a connective tissue capsule that surrounds large, cavernous ducts lined by stratified squamous epithelium and acini. The acini are composed of eosinophilic, pale, foamy, secretory sebaceous cells with dark nuclei and peripheral, flat, elongated basal cells (Ponmanickam et al. 2016). Gourbal and Gabrion (2006) investigated the histomorphological alterations induced by the parasite (Taenia crassiceps) in male preputial and female clitoral glands of mice, and found disorganization of the acinar cells of male preputial gland, but no impact was reflected in the histomorphology of the female clitoral glands. It was suggested that this difference between infected male and female mice might be related to the different sex hormones (Gourbal and Gabrion 2006). According to Ramachandran et al (2018) the histological preparations of the preputial gland of M. meltada show acinar cells with sebum. Immunohistochemical analysis revealed the presence of $\alpha_{2 u}$-globulin, the carrier protein, in the sebum. The sebum is secreted into the central duct of the preputial gland and excreted through the urethra when it contains volatile compounds (e.g., farnesol and 6-methyl-1-heptanol) for chemical communication. Barring this, there has been no focused study of comparative histomorphology of male preputial glands and female clitoral glands. Hence, the present investigation was taken up to explore the sex-specific differences in the histomorphology of preputial and clitoral glands of soft-furred field rat, M. meltada.

\section{Materials and Methods}

\section{Animal}

Adult male and female rats Millardia meltada were collected from paddy fields in and around Madurai and Tiruchirappalli districts and housed separately in polypropylene cages $(40 \times 25 \times 15 \mathrm{~cm})$ with rice husk to $2 \mathrm{~cm}$ height as bedding material, at $12 \mathrm{~h}$ light: $12 \mathrm{~h}$ dark cycle, and temperature $24 \pm 1{ }^{\circ} \mathrm{C}$, when they were fed with formulated rat pellet food (Sai Durga Feeds and Foods, Bangalore) and water ad libitum. The bedding material was changed twice a week. The study was conducted under approval from the Institutional Animal Ethics Committee (IAEC) of Bharathidasan University, Tiruchirappalli, India (Approval No. BDU/IAEC/2012/71).

\section{Dissection of preputial and clitoral glands}

Six adult intact male and female rats were dissected under sodium pentabarbital anesthesia (Fig. 1). The preputial and clitoral glands were removed carefully, and the rats were sacrificed under excess ketamine $(2 \mathrm{mg} / \mathrm{kg}$, iv). The length and width of the glands were measured using a graph sheet, and then weighed in a monopan balance (Rajagopal and Archunan 2011).

\section{Histological study}

Immediately thereafter the glands were fixed separately in Bouin's fluid and subjected to routine histological analysis (Humason 1979). After several changes of 70\% alcohol, until the yellow color of Bouin's fluid disappeared, the tissues were dehydrated by passing through ascending grades of alcohol, cleared in xylene, infiltrated with molten paraffin, and finally embedded in paraffin wax. Transverse and longitudinal sections at 3-5 $\mu \mathrm{m}$ 

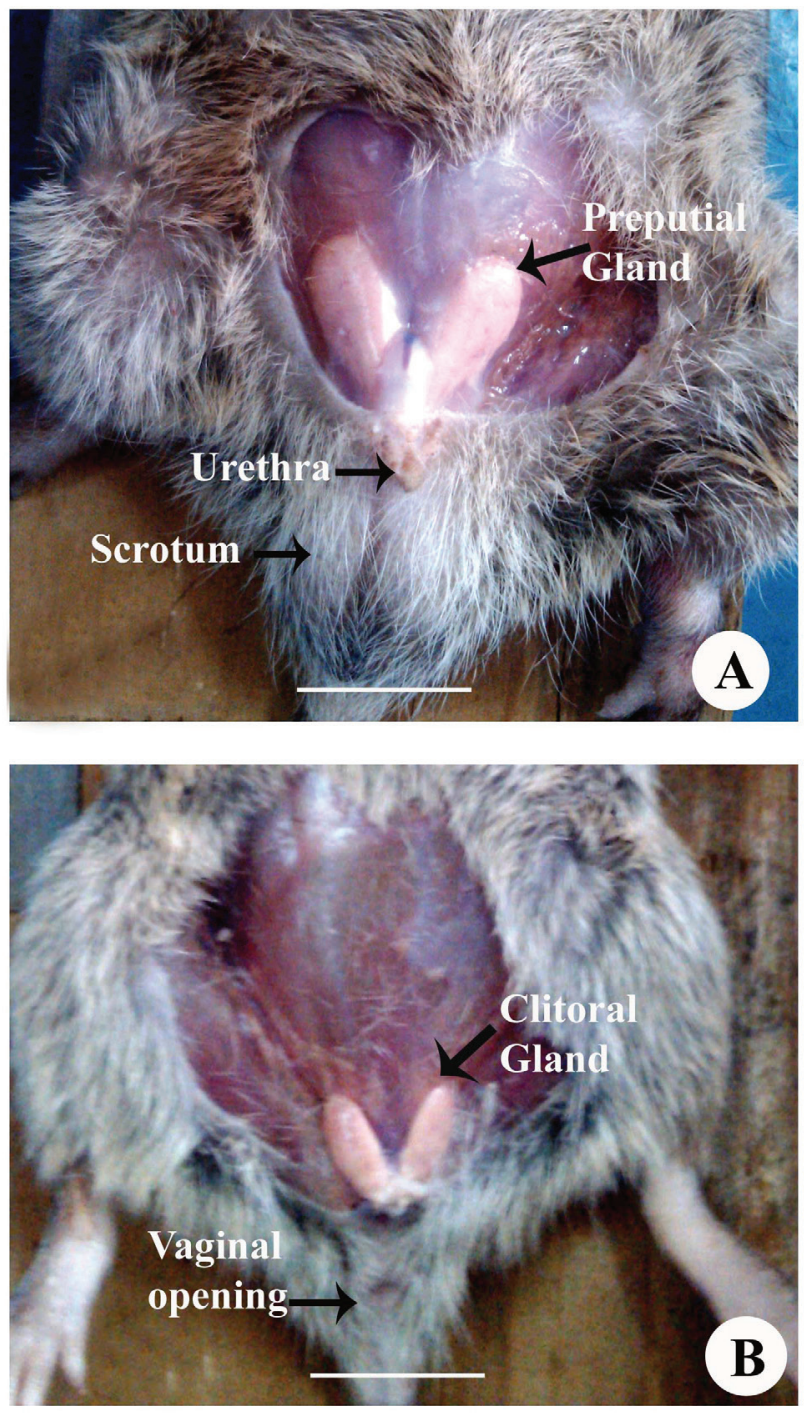

Figure 1. Ventral dissection of male (A) and female (B) soft-furred field rat, Millardia meltada, showing preputial and clitoral glands, respectively. Bar $=1 \mathrm{~cm}$

thickness were obtained using a rotary microtome (Leica, Germany). The sections, thus obtained, were stained in Harris hematoxylin and eosin, dehydrated using alcohol, cleared in xylene and mounted in DPX adhesive resin.

\section{Data processing}

The data with respect to length, width and weight were used to calculate the respective means and standard deviations. Paired sample $t$-test was conducted and $p$ value less than 0.05 was taken to indicate significant difference.

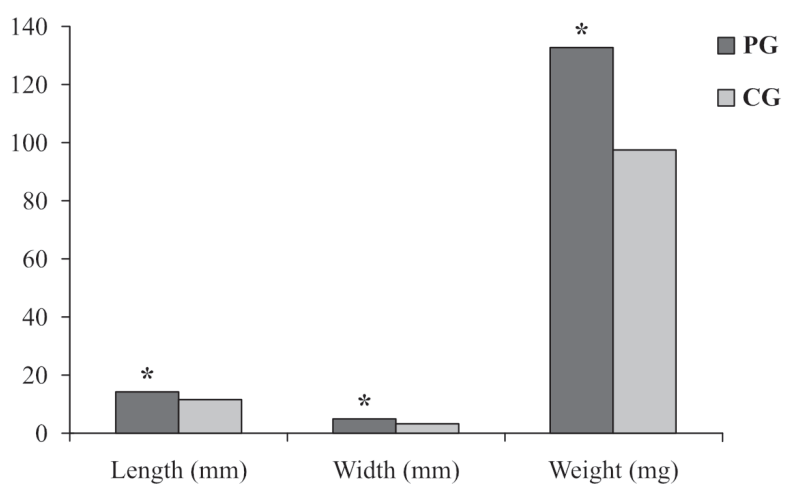

Figure 2. Mean values of the morphometric parameters (length, width, and weight) of male preputial (PG) and female clitoral glands (CG). * $p$ $<0.05$, preputial gland (PG) compared to clitoral gland (CG).

\section{Results}

\section{Morphological observation}

The scent glands are located underneath the dermis and embedded in the subcutaneous fat. The preputial glands are bilateral and located in the subcutaneous adipose tissue, laterocranial to the penis (Fig. 1A), while the clitoral glands are situated on either side of the clitoris and immediately adjacent to the inguinal portion of the mammary gland (Fig. 1B). The paired glands (both preputial and clitoral) are yellowish-brown, pear-shaped, and dorsoventrally compressed. The preputial gland of adult male rat measured $14.16 \pm 3.81 \mathrm{~mm}$ long, and $4.41 \pm$ $1.05 \mathrm{~mm}$ wide and weighed $132.6 \pm 12.10 \mathrm{mg}$. The clitoral gland of adult female rat measured $11.25 \pm 2.13 \mathrm{~mm}$ long, and $2.95 \pm 0.75 \mathrm{~mm}$ wide and weighed $97.5 \pm 10.85 \mathrm{mg}$. Thus, the morphometric parameters [length: $\mathrm{t}=10.03$, $\mathrm{df}=11$; width: $\mathrm{t}=5.99, \mathrm{df}=11$ and weight: $\mathrm{t}=13.47$, df $=11$ ] of preputial and clitoral glands differ significantly $(p<0.05)$ (Fig. 2).

The density and diameter of sebaceous glands were found to vary between preputial gland of male and clitoral gland female rats under microscopic investigation. The paired t-test clearly showed that the density of sebaceous gland is significantly $(\mathrm{t}=7.97, \mathrm{df}=11, p<0.05)$ higher in male preputial gland $\left(14.65 \pm 1.14\right.$ units $\left./ \mathrm{mm}^{2}\right)$ than the female clitoral gland $\left(8.35 \pm 0.52\right.$ units $\left./ \mathrm{mm}^{2}\right)$. Further, the diameter of sebaceous gland varied significantly $(\mathrm{t}=$ $13.58, \mathrm{df}=11, p<0.05)$ in the male preputial gland $(29.90$ $\pm 1.56 \mu \mathrm{m})$ compared to female clitoral gland (18.71 \pm $\mu \mathrm{m})$. The density $\left(6.44 \pm 0.48\right.$ units $\left./ \mathrm{mm}^{2}\right)$ and diameter $(24.69 \pm 0.88 \mu \mathrm{m})$ of apocrine gland was also noted in the preputial glands of male rat.

\section{Histological observation}

The secretory units of preputial gland are formed of se- 
Rajagopal et al.
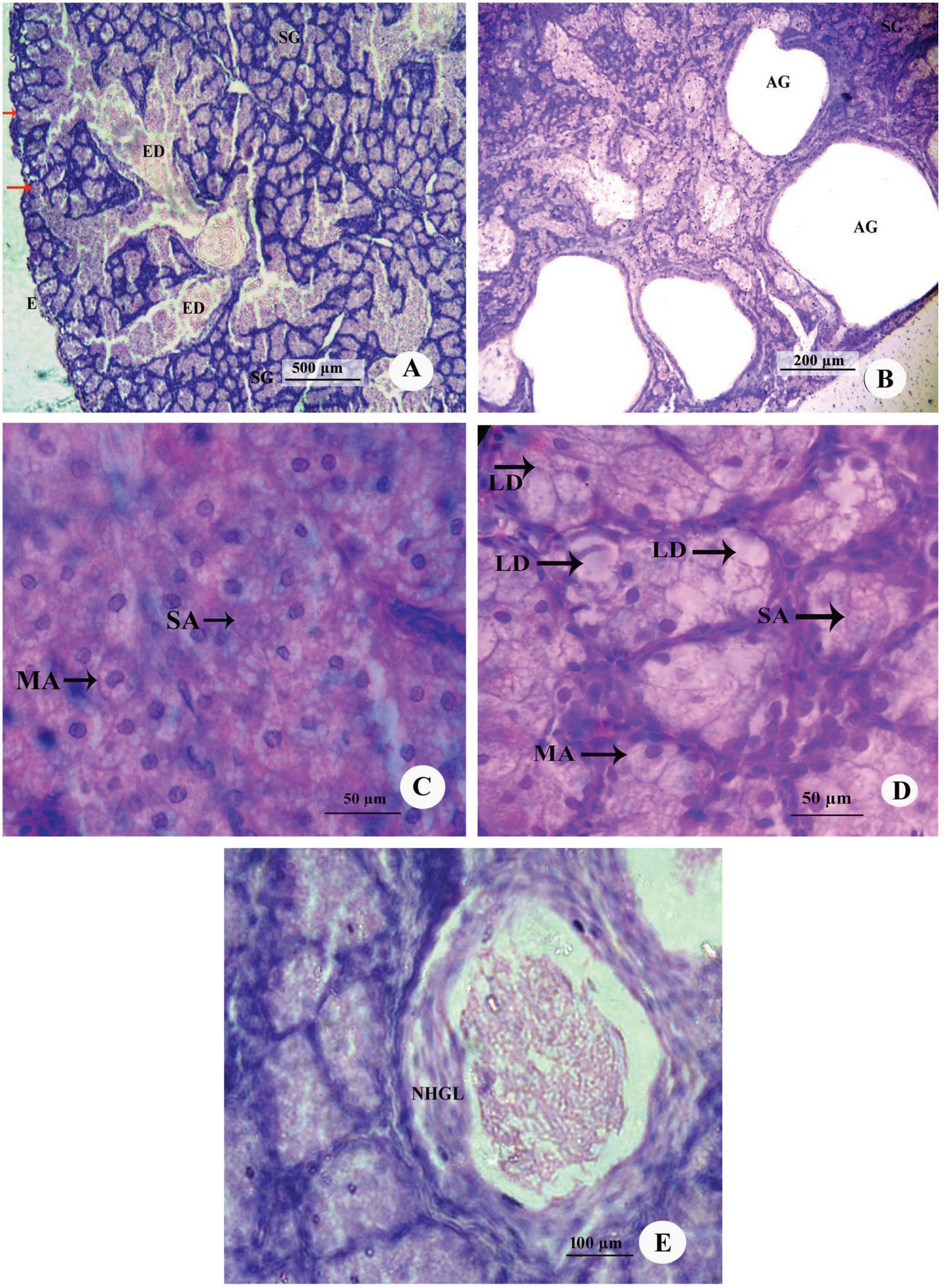

Figure 3. Hematoxylin-eosin-stained sections of preputial gland of male rat. A, Sebaceous glandular lobular portion; B, Apocrine glandular lobular portion; C, Ordinary sebaceous glandular lobules; D, Modified sebaceous glandular lobules; E, Sebaceous glandular portion with a secretory acinus with the lumen distended with secretory material released from the cells by necrosis. Abbreviations: ED: Excretory duct; E: Epidermis; SG: Sebaceous gland; AG: Apocrine gland; NHGL: Normal alveolar holocrine glandular lobules; SA: Serous acini; MA: Mucus acini; LD: Lipid droplets. 

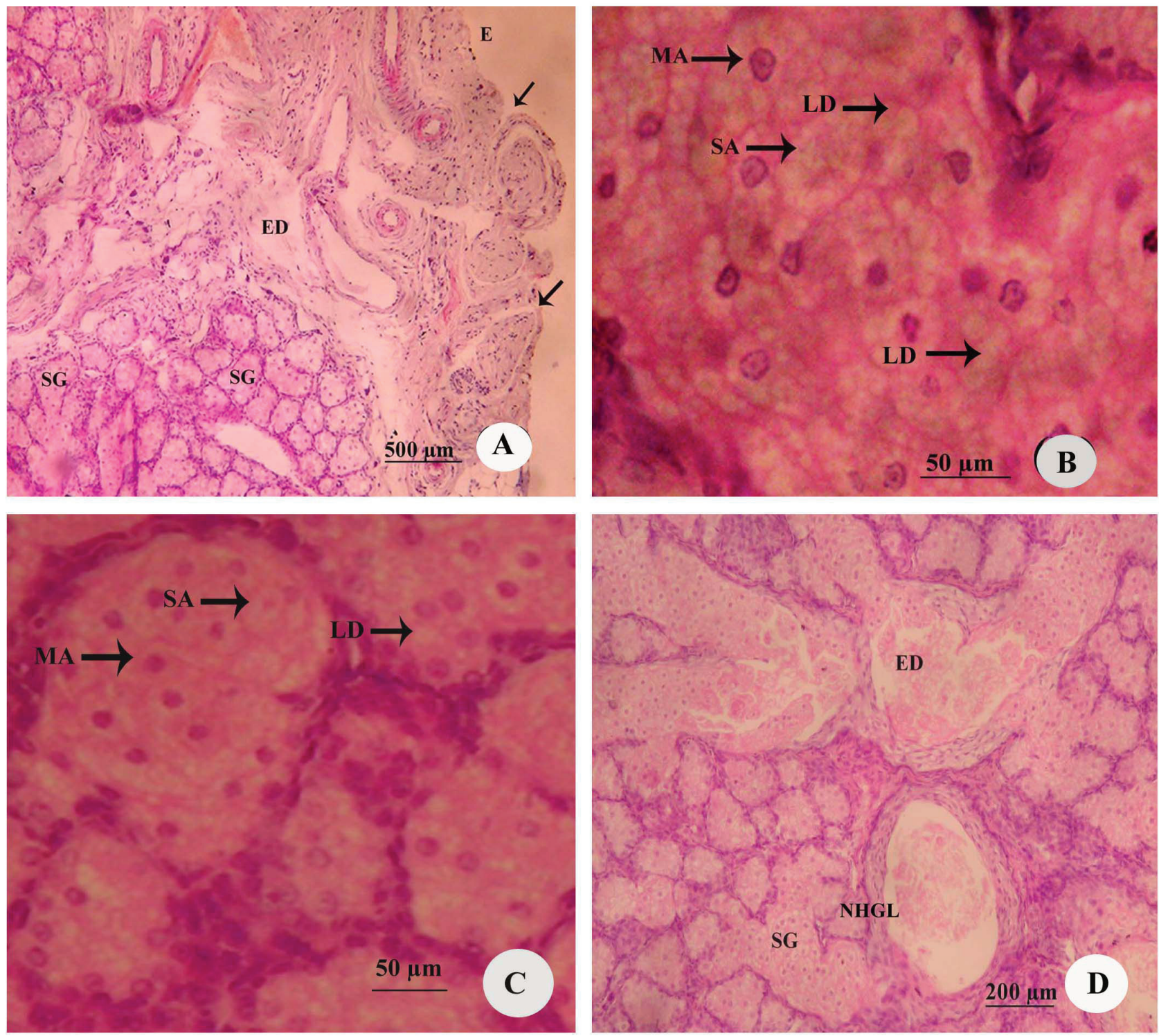

Figure 4. Hematoxylin-eosin stained sections of clitoral gland of female rat. A, Sebaceous glandular lobules; B, Ordinary sebaceous glandular lobules; C, Modified sebaceous glandular lobules; D, Sebaceous glandular portion with a secretory acinus distended with secretory material released from cells by necrosis. Abbreviations: ED: Excretory duct; E: Epidermis; SG: Sebaceous gland; NHGL: Normal alveolar holocrine glandular lobules; SA: Serous acini; MA: Mucus acini; LD: Lipid droplets.

baceous secretory lobules and apocrine secretory lobules (Fig. 3A, B). On the other hand, the secretory units of clitoral glands are only sebaceous glandular lobules (Fig. 4A). The sebaceous secretory gland lobules of preputial as well as clitoral glands are formed of both ordinary and modified sebaceous glandular lobules (Fig. 3C, D; Fig. 4B, C). The ordinary sebaceous glandular lobules are small and superficially located. The secretory acini formed of the modified sebaceous glandular lobules are teardropshaped and very large as compared to acini formed of the ordinary type of glandular lobules. The modified sebaceous glandular lobules consist of four types of cells: peripheral cells, differentiating cells, mature cells and necrotic cells. Peripheral cells are flat with oval nucleus and form a thin layer. Differentiating cells are large, polyhedral in shape, and contain centrally located nucleus in the eosinophilic cytoplasm. The differentiating cells progressively transform into mature cells which have a foamy cytoplasm. Necrotic cells possess pyknotic nuclei and on lysis release the content into the lumina. 
In both preputial and clitoral glands the secretory material of sebaceous cells is released by holocrine mechanism into the branched tubuloalveolar system wherein the secretory acini open into numerous lateral ducts that fuse to form a wide central duct through which the secretion is conveyed to the lumen of the pouch (Fig. 3E; Fig. 4D). At the distal end of the gland the central duct, containing membrane-bound secretory granules, opens onto the skin at the transition of the parietal layer of the prepuce and the end of the urethra in the tip of the penis in the case of preputial gland and vagina in the case of clitoral gland. The sebaceous type acinar cells look foamy, with small granules in the cytoplasm. The glandular epithelioid acini are composed of flat basal cells adjacent to the basement membrane and lateral to the secretory cells in the central parts of the acini. The cells are closer to the center of the alveoli and become progressively large, and the cytoplasm is distended with fat droplets due to which the cytoplasm takes honeycomb-like appearance (Fig. 3C, D; Fig. 4B, C). The apocrine secretory units of preputial glands consist of an inner layer of cuboidal cells that rest directly on the basement membrane and an outer layer of myoepithelial cells. The cuboidal cells that line the secretory acini possess acidophilic vacuolated cytoplasm and spherical, centrally located nucleus. The cells often exhibit apical protrusions. The secretory material is released in the form of droplets by apocrine mechanism and get stored in the lumina (Fig. 3B).

\section{Discussion}

The significant difference of the morphometric parameters (i.e., length, width, and weight) between preputial and clitoral glands is to be perceived as manifestation of the sexual difference of the pheromone secreting glands between male and female soft-furred field rat which is in agreement with the condition in Iranian sheep (Abbasi et al. 2009), Egyptian sheep (Awaad et al. 2015), Awassi sheep (Yilmaz et al. 2017), and Bandicoot rat (Ponmanickam et al. 2016). In another context, the preorbital gland length, width and weight were higher in dominant male (i.e., adult) than subordinate male (i.e., sub-adult and adolescent) blackbucks (Rajagopal and Archunan 2011). According to Zhang et al. (2008) the scent glands of rats do not exhibit sexual differences, but gonadectomy resulted in significant decrease of size of the scent glands of both sexes. The dominant male mice are characterized by higher testosterone levels and heavier preputial glands than subordinate male mice (Mckinney and Desjardins 1973). Further, the diameter of sebaceous gland has a higher in size in male preputial gland compared to female clitoral gland. It is reported that the higher development of the sebaceous gland in the male fallow deer could depend on the higher social responsibility (dominance hierarchy) / production of testosterone (Schaal 1982; Moawad 2016). Therefore, the larger size and higher weight of male scent gland are to be taken to reflect manifestation of the androgen-support. These findings indicate that the size of scent glands is influenced by sex hormones and function to express their respective reproductive statuses to the opposite sex.

Microscopic examination of preputial and clitoral glands revealed a clear fibrous capsule around each. The histological structure of preputial gland is heterogeneous in that it has holocrine sebaceous and apocrine secretory cells, whereas sebaceous secretory cells alone are present in the entire clitoral gland. This is a clear histomorphological manifestation of sexual dimorphism. Similar findings have been made on intermandibular glands of lesser mouse deer (Agungpriyono et al. 2006), infraorbital gland of the barking deer (Adnyane et al. 2011) and preorbital gland of the blackbuck (Rajagopal and Archunan 2011), but the finding contradicts the observation made on infraorbital glands of the Japanese serow (Atoji et al. 1987), and Formosan serow (Atoji et al. 1996) and interdigital glands of sheep (Misk and Misk 2013). According to Zhang et al. (2008) rat male scent gland secretion is rich in squalene compared to female gland, whereas farnesol content was lower in male scent gland than female gland. Squalene is a female-attractant and farnesol a male-attractant. Thus, these compounds are sex-specific (Zhang et al. 2008). One of our studies showed that the amount of protein was higher in preputial glandular secretion than clitoral gland (Archunan et al. 2004). In addition, though the $20 \mathrm{kDa}$ protein was found in both male and female scent glands of rat, the intensity was higher in male than female and it was suggested that this protein is indeed a sex-associated protein (Archunan et al. 2004). Thus, this study substantiates histological difference between the preputial and clitoral glands of soft-furred field rat indicating sexual dimorphism. We suggest that the sex-specific nature of pheromone and protein may be due to the variations in the histoarchitectutre of the glands and sex hormonedependence of their morphology and secretion.

As far as sebaceous secretory portion of both preputial and clitoral glands are concerned, we found ordinary as well as modified glandular lobules. The modified sebaceous glandular lobules have been found in the scent glands of several mammalian species such as antelope Madoqua sp. (Richter 1971), antelope/red duiker Cephalophus natalensis (Mainoya 1978), royal antelope Neotragus pygmaeus (Kuhn 1976), steenbok Raphicerus campestris (Cohen and Gerneke 1976), and oribi Ourebia ourebi (Sokolov et al. 1994). Nevertheless, both modified and ordinary sebaceous glandular lobules produce sebum which is an oily/waxy 
substance documented to be concerned with olfactory communication in several mammals (Rajagopal and Archunan 2011; Yilmaz et al. 2017; Ramachandran et al. 2018; SankarGanesh et al. 2018). The modified sebaceous glandular lobules of the preputial glands of male mouse are larger than in the female clitoral glands, and this feature is greatly influenced by a variety of hormones (Bronson and Caroom 1971). An immunohistochemical study revealed the presence of $\alpha_{2 u}$-globulin in the sebum produced in modified sebaceous glandular lobules of preputial gland. The sebum is discharged by holocrine mechanism into the central duct of the preputial gland and excreted through the urethra. The putative pheromones (e.g., farnesol) are bound to the $\alpha_{2 \mathrm{u}}$-globulin (Ramachandran et al. 2018). Ilayaraja et al. (2014) conducted research to confirm that farnesol binds with the $\alpha_{2 u}$-globulin efficiently. The present study suggests that sebaceous secretory cells of scent glands of male and female rats secrete different odoriferous volatile substances. These substances provide for olfactory communication between conspecifics (Kannan et al. 1998; Zhang et al. 2008; Achiraman et al. 2011; Ramachandran et al. 2018).

In the present study, the apocrine glandular lobules were found only in the preputial gland, i.e., male. The myoepithelial cells observed in the apocrine glandular lobules revealed evidence of apocrine secretion of the secretory cells. The myoepithelial cells surround the secretory acini and facilitate discharge of the secretory material by way of their contraction (Abbasi et al. 2009; Awaad et al. 2015). Apocrine glands have been reported in sheep, horse, antelope, cow and a few marsupials, and these glands function as scent glands to produce pheromones (Robertshaw 1987; Rajagopal and Archunan 2011). According to Satoh et al. (1994) the myoepithelial cells of apocrine glands are endowed with capability to provide compression pressure for glandular expulsion of the secretory material. It is remarkable that the pheromonal compounds derived mainly from the sebaceous gland on discharge to the outside can adhere to objects in view of the carrier proteins (Atoji et al. 1987; Agungpriyono et al. 2006; Rajagopal and Archunan 2011). Previous studies have shown that the lumen of the apocrine gland is filled with dense secretory materials which are discharged directly onto the excretory duct through prepuce (Karahan et al. 2007; Abbasi et al. 2009; Rajagopal and Archunan 2011; Awaad et al. 2015). The present study suggests that the apocrine secretory gland in the male rats would produce sex-specific volatile substances as an aspect of the preputial glands that might facilitate better adhesion capacity and high persistence in the scented site during the expression of territorial/scent marking in male rats.

To the best of our knowledge this is the first comprehensive comparative histomorphological analysis of preputial and clitoral glands, the male and female scent glands respectively, of soft-furred field rat. Preputial glands of male rat are relatively larger in size than the clitoral glands of female rat. Preputial gland is composed of sebaceous and apocrine secretory glandular lobules whereas clitoral gland is made up only of sebaceous glandular lobules. These findings indicate that the scent glands of the soft-furred male and female field rats show sexual dimorphism. Based on the morphometric and histomorphological observation, we conclude that the soft-furred field rat scent glands (preputial and clitoral) would play role in the production of sex-specific volatile substances through sebaceous and apocrine secretory glands for olfactory communication. Further ultrastructural and immunohistochemical studies of different rodent species and correlation between pheromone production and behaviors would throw light on importance of these glands in pheromonal communication which can be made use of in the rodent pest management programs.

\section{Acknowledgements}

The authors thank the Principal and the Management of Thiagarajar College (Autonomous), Madurai, for providing facilities and the constant encouragement. GA thanks the University Grants Commission (UGC), New Delhi, for the award of UGC-BSR Faculty Fellowship. The authors declare that there is no conflict of interest.

\section{References}

Abbasi M, Gharzi A, Mohammadzadeh S, Karimi H (2009) Morphology and histology of the interdigital gland in an Iranian native breed of sheep. J Anim Vet Adv 8:1157-1161.

Achiraman S, Archunan G, Abirami B, Kokilavani P, Suriyakala U, SankarGanesh D, Kamalakkannan S, Kannan S, Habara Y, Sankar R (2011) Increased squalene concentrations in the clitoral gland during the estrous cycle in rats: an estrus-indicating scent mark? Theriogenology 76:1676-1683.

Adnyane IKM, Ziki ABZ, Noordin MM, Wahyuni S, Agungpriyono S (2011) Morphological study of the infraorbital gland of the male barking deer, Muntiacus muntjak. Afr J Biotechnol 10:17891-1797.

Agungpriyono S, Atoji Y, Yamamoto Y, Zuki AB, Novelino $S$ (2006) Morphology of the intermandibular gland of the lesser mouse deer, Tragulus javanicus. Anat Histol Embryol 35:325-333.

Alxandre-Pires G, Martins C, Galvao AM, Correia M, Ramilo D, Quaresma M, Ligeiro D, Nunes T, Calderia RM, Ferreira Dias G (2014) Morphological aspects and 
expression of estrogen and progesterone receptors in the interdigital sinus in cyclic ewes. Microsc Res Tech 77:313-325.

Archunan G (2009) Vertebrate pheromones and their biological importance. J Exp Zool India 12:227-239.

Archunan G, Kamalakkannan S, Achiraman S, Rajkumar R (2004) Identification of glandular (preputial and clitoral) proteins in house rat (Rattus rattus) involved in pheromonal communication. Indian J Exp Biol 42:1032-1035

Archunan G, Ponmanickam P (2010) Preputial gland: A potent pheromone source in rodents. In Logan EW, Jason MA, Eds., The Biology of Odors: Sources, Olfaction and Response. Nova Science Publishers, Hauppauge, New York, 321-340.

Atoji Y, Sugimura M, Suzuki Y (1987) Lectin histochemical study on the infraorbital gland of the Japanese serow ( $\mathrm{Ca}$ pricornis crispus). Acta Morphol Neerl Scand 25:201-213.

Atoji Y, Yamamoto Y, Suzuki Y (1996) Infraorbital glands of a male Formason serow (Capricornis crispus swinhoei). Eur J Morphol 34:87-94.

Awaad AS, Tawfiek MG, Moawad UK, Abdel Razek AH, Abedellaah BA (2015) Morphohistological and surgical anatomy of the sinus interdigitalis in Egyptian native breeds of sheep. Beni-Suef Univ J Basic Appl Sci 4:157166.

Balakrishnan M, Alexander KM (1985) Sources of body odour and olfactory communication in some Indian mammals. Indian Rev Life Sci 5:277-313.

Bronson FH, Caroom D (1971) Preputial gland of the male mouse: attractant function.J Reprod Fertil 25:379-382.

Brouette-Lahlou I, Godinot F, Vernet-Maury E (1999) The mother rat's vomeronasal organ is involved in detection of dodecyl propionate, the pup's preputial gland pheromone. Physiol Behav 66:427-436

Cohen M, Gerneke DH (1976) Preliminary report on the intermandibular cutaneous glandular area and the infraorbital gland of the steenbok. J S Afr Vet Assoc 47:35-37.

Gourbal BEF, Gabrion C (2006) Histomorphological study of the preputial and clitoral glands in BALB/c mice with experimental Taenia crassiceps infections. J Parasitol 92:189-192.

Greaves JH (1989) Rodent pest and their control in the near East. FAO of the UN plant production and protection, Issue No. 95. Food and Agricultural Organization, Rome, Italy.

Humason GL (1979) Animal Tissue Techniques, 4th Ed. W. H. Freeman, San Francisco.

Ilayaraja R, Rajkumar R, Rajesh D, Muralidharan AR, Padmanabhan P, Archunan G (2014) Evaluating the binding efficiency of pheromone binding protein with its natural ligand using molecular docking and fluorescence analysis. Sci Rep 4:1-7.

Kamalakkannan S, Achiraman S, Rajkumar R, Ramesh- kumar K, Archunan G (2006) Identification of sexassociated protein in the preputial gland of house rat: a new insight in RPM. Acta Physiol Hung 93:145-152.

Kannan S, Rameshkumar K, Archunan G (1998) Sex attractants in male preputial gland: Chemical identification and their role in reproductive behaviour of rats. Curr Sci 74:689-691.

Kannan S, Archunan G (2001) Chemistry of clitoral gland secretions of the laboratory rat: Assessment of behavioural response to identified compounds. J Biosci 26:247-252.

Karahan S, Yildiz D, Bolat D (2007) Scanning electron microscopic features of the ovine interdigital sinus. Acta Vet Hung 55:417e24.

Knoblaugh SE, True L, Tretiakova M, Hukkanen RR (2018) Comparative anatomy and histology. In Treuting PM, Dintzis SM, Montine KS, Eds., A Mouse, Rat, and Human Atlas. Academic Press, London, UK, 335-365.

Kuhn HJ (1976) Antorbitaldruse und tranennasengang von Neotragus pygmaeus. Z Säugetierkde 41:369-380.

Mainoya JR (1978) Histological aspect of preorbital and interdigital glands of red duiker (Cephalopus natalensis). East Afr Wildl J 16:256-272.

McKinney TD, Desjardins C (1973) Postnatal development of the testis, fighting behavior and fertility in house mice. Biol Reprod 9:279-294.

Misk TN, Misk NA (2013) Surgical excision of interdigital pouch and cyst in sheep. Int J Vet Med Res Rep 1:1-8.

Moawad UK (2016) Morphological, histochemical and morphometric studies of the preorbital gland of adult male and female Egyptian native breeds of sheep (Ovis aries). Asian J Anim Vet Adv 11:771-782.

Ponmanickam P, Archunan G (2006) Identification of $\alpha_{2 u^{-}}$ globulin in the rat preputial gland by MALDI-TOF analysis. Indian J Biochem Biophys 34:319-322.

Ponmanickam P, Jebamercy G, Archunan G, Kannan S (2009) Detection of $\alpha_{2 u}$-globulin in rat pup preputial gland by MALDI-TOF mass spectrometry. Curr Zool 55:296-300.

Ponmanickam P, Palanivelu K, Govindaraj S, Baburajendran R, Habara Y, Archunan G (2010) Identification of testosterone-dependent volatile compounds and proteins in the preputial gland of rat Rattus norvegicus. Gen Comp Endocrinol 167:35-43.

Ponmanickam P, Muniasamy S, Rajagopal T, Rengarajan RL, Archunan G (2016) Identification of $\mathrm{GABA}_{\beta}$ receptor protein and farnesol in the preputial gland of bandicoot rat (Bandicota indica). Adv Zool Bot 4:37-45.

Rajagopal T, Archunan G (2011) Histomorphology of preorbital gland in territorial and non-territorial male blackbuck, Antelope cervicapra L., a critically endangered species. Biologia 66:370-378.

Rajkumar R, Ilayaraj R, Liao CC, Archunan G, Achiraman S, Prakash S, Ng WV, Tsay YG (2010) Detection of alpha $(2 \mathrm{u})$-globulin and its bound putative pheromones in 
the preputial gland of the Indian commensal rat (Rattus rattus) using mass spectrometry. Rapid Commun Mass Spectrum 24:721-728.

Ramachandran R, Achiraman S, Rajagopal T, SankarGanesh D, Kamalakkannan S, Ponmanickam P, Rajkumar R, Ramya Vaideki G, Padmanabhan P, Archunan G (2018) Localization of $\alpha_{2 u}$-globulin in the acinar cells of preputial gland, and confirmation of its binding with farnesol, a putative pheromone, in field rat (Millardia meltada). PLoS One 13:1-15.

Robertshaw D (1983) Apocrine sweat glands. In Goldsmith LA, Ed., Biochemistry and Physiology of the Skin. Oxford University Press, New York, 642-653.

Richter J (1971) Unterschungen an antorbitaldrusen von Madaqua (Bovidae; Mammalia). Z Säugetierkd 36:334-342.

SankarGanesh D, Ramachandran R, Ashok R, Saravanakumar VR, Sukirtha R, Archunan G, Achiraman S (2018) Buck odor production in the cornual gland of male goat, Capra hircus- Validation with histoarchitecture, volatile and proteomic analysis. Indian J Biochem Biophys 55:183-190.
Satoh Y, Oomori Y, Ishikawa K, Ono K (1994) Configuration of myoepithelial cells in various exocrine glands of guinea pigs. Anat Embryol 189:227-236.

Selvaraj R, Archunan G (2006) Efficacy of male scent glands and urine in masking poison bait odour in female house rats, Rattus rattus. J Pest Sci 79:255-258.

Sokolov VE, Chernova OF, Fekadu K (1994) The skin of some Ethiopian ungulates. Russian Academy of Science, Moscow, 147

Yilmaz B, Yilmaz R, Demircioglu I, Arican I (2017) Morphological and histological structure of the interdigital gland in Awassi sheep (Ovis aries). Turk J Vet Anim Sci 41:380-386.

Zhang JX, Sun L, Zhang JH, Feng ZY (2008) Sex- and gonadaffecting scent compounds and 3 male pheromones in the rat. Chem Senses 33:611-621. 
